\title{
Staffing and job satisfaction: nurses and nursing assistants
}

\author{
BEATRICE KALISCH PhD, RN, FAAN ${ }^{1}$ and KYUNG HEE LEE RN, MPH, GNP, PhD ${ }^{2}$ \\ ${ }^{1}$ Titus Distinguished Professor of Nursing and Director, Innovation and Evaluation, School of Nursing, University \\ of Michigan, Ann Arbor, MI, USA and 'Postdoctoral Fellow, School of Nursing, Duke University, Durham, NC, \\ USA
}

Correspondence

Beatrice J. Kalisch

Nursing Business and Health

Systems

University of Michigan School of

Nursing

400 N. Ingalls Street

Ann Arbor

Michigan 48103

USA

E-mail:bkalisch@umich.edu
KALISCH B. \& LEE K.H. (2014) Journal of Nursing Management 22, 465-471.

\section{Staffing and job satisfaction: nurses and nursing assistants}

Aim The aim of this study was to examine the relationship between staffing and job satisfaction of registered nurses (RNs) and nursing assistants (NAs).

Background Although a number of previous studies have demonstrated the link between the numbers of patients cared for on the last shift and/or perceptions of staffing adequacy, we could find only one study that utilized a measure of actual staffing (opposed to perceptions of staffing adequacy) and correlated it with job satisfaction of registered nurses.

Methods This cross-sectional study included 3523 RNs and 1012 NAs in 131 patient care units. Staff were surveyed to determine job satisfaction and demographic variables. In addition, actual staffing data were collected from each of the study units.

Results Hours per patient day was a significant positive predictor for registered nurse job satisfaction after controlling for covariates. For NAs, a lower skill mix was marginally significant with higher job satisfaction. In addition, the more work experience the NAs reported, the lower their job satisfaction.

Conclusion Adequate staffing levels are essential for $\mathrm{RN}$ job satisfaction whereas $\mathrm{NA}$ job satisfaction depends on the number of assistive personnel in the mix of nursing staff.

Implications for Nursing Management Two implications are (1) providing adequate staffing is critical to maintain $\mathrm{RN}$ job satisfaction and (2) the NA job needs to be re-engineered to make it a more attractive and satisfying career.

Keywords: job satisfaction, nurse, nursing assistant, staffing

Accepted for publication: 2 August 2012

\section{Introduction}

Job satisfaction is a critical issue for nursing staff, administrators, as well as patients as it has been associated with turnover, quality of nursing care (Khowaja et al. 2005, Murrells et al. 2005), patient outcomes, including mortality rates and failure to rescue (Adams \& Bond 2000, Best \& Thurston 2004), as well as patient satisfaction with nursing care (Seago 2002).
High turnover is a problem which impacts the quality of nursing care provided by the nursing team (Castle \& Engberg 2005).

Studies have examined factors that are correlated with job satisfaction and quality of care. Previous studies have shown a clear linkage between perceptions of staffing adequacy and job satisfaction (Dunn et al. 2005, Khowaja et al. 2005, Lapane \& Hughes 2007, Anderson et al. 2009, Rochefort \& Clarke 
2010, Kalisch et al. 2011). Little research however has examined the relationship between unit-level actual staffing [hours per patient day (HPPD) and the skill mix] and job satisfaction. In addition, while many studies have examined job satisfaction of registered nurses (RNs), few have looked at what leads to job satisfaction of nursing assistants (NAs). The present study focuses on the association between unit-level staffing and job satisfaction of RNs and NAs.

\section{Background}

A number of previous studies have examined the relationship between job satisfaction and staffing levels of RNs. Aiken et al. (2002a) studied 10319 nurses working on medical-surgical units in 303 hospitals in five countries. They found that the more patients the nurse cared for, the higher the job dissatisfaction. In another study of 168 non-federal adult general hospitals in Pennsylvania, each additional patient per nurse was associated with a $15 \%$ increase in the odds of job dissatisfaction (Aiken et al. 2002b).

Similarly Sheward et al. (2005) surveyed 4721 RNs in Scotland and England. Using the measure of how many patients taken care of on the last shift and how satisfied they were with nursing as a career, their current job and their intent to leave their current position were examined. They found that the fewer the patients, the greater the job satisfaction of RNs.

Shaver and Lacey (2003) studied 600 RNs and 600 Licensed Practical Nurses (LPNs) and found that higher patient loads, was negatively associated with satisfaction with the current job but not satisfaction with the career. Rafferty et al. (2007) surveyed 3984 nurses in 30 English acute hospitals to determine the relationship between nurse-reported numbers of patients during the last shift worked and job satisfaction. They concluded that RNs in the highest quartile of nurse-reported patient-to-nurse ratios were twice as likely to report job dissatisfaction. Similarly, Seo et al. (2004) reported a causal model of job satisfaction with a sample of 353 nurses in two Korean hospitals and found that high workload was significantly associated with lower job satisfaction.

Other studies have linked perceptions of staffing adequacy with job satisfaction of RNs (as opposed to reported numbers of patients cared for on the last shift or measures of actual staffing) (Dunn et al. 2005, Khowaja et al. 2005, Lapane \& Hughes 2007, Anderson et al. 2009, Rochefort \& Clarke 2010). In another study in Canada, Rochefort and Clarke (2010) examined the relationship between work environment characteristics and job satisfaction using 633 RNs in nine neonatal intensive care units. They found that higher nurse perceived staffing and resource adequacy, one of the factors in the Nursing Work Index developed by Aiken and Patrician (2000), predicted higher job satisfaction.

There are only a few reports of studies of the job satisfaction of NAs and they have been conducted in nursing homes rather than acute care hospitals. In one study in nursing homes, nearly $40 \%$ of NAs were not satisfied with their job and $30 \%$ had plans to leave (Parsons et al. 2003). As factors that lead to NA job satisfaction in nursing homes, coworker support, teamwork and NA staffing levels (i.e. full-time equivalent NAs per 100 residents) were found as contributing factors on NA job satisfaction (Parsons et al. 2003, Castle et al. 2007). Lapane and Hughes surveyed both 756 RNs and 1610 NAs in nursing homes and found that not having enough staff was the highest job stressor leading to job dissatisfaction reported by both RNs and NAs (2007).

Taken together, several limitations of the previous studies on RN and NA job satisfaction were found. These studies have all included at the individual or hospital-level data. To our knowledge, only one study of staffing levels and nurse job satisfaction has utilized unit-level data (Best \& Thurston 2004), and they found that a higher skill mix was linked to greater job satisfaction. However, this study was conducted with Canadian nurses and did not control for staff characteristics (e.g. age, gender, education and experience), in spite of findings in other studies which have pointed to a relationship between demographic characteristics and job satisfaction (Blegen 1993, Dunn et al. 2005, Sheward et al. 2005, Bjork et al. 2007, Li \& Lambert 2008). They also did not control for patient acuity, limiting their data analysis to correlations between job satisfaction and staffing.

In addition, only a few studies have addressed NA job satisfaction and these have been conducted in nursing homes not in acute care settings. In this study, we investigated the relationship between unit-level staffing and job satisfaction of both RNs and NAs working in acute care settings controlling for demographic variables and patient acuity. This study included HPPD and the skill mix as unit-level staffing variables; we have not found a study to examine the association between HPPD and job satisfaction.

As potential covariates, $\mathrm{RN}$ job satisfaction has been found to vary by age, gender, nursing education and years of job experience. Older female RNs with longer nursing job experience have been found to be more 
satisfied with their job (Blegen 1993, Dunn et al. 2005, Sheward et al. 2005, Bjork et al. 2007, Li \& Lambert 2008). Older NAs were also likely to maintain their job with higher satisfaction (Wallace \& Brubaker 1982, Parsons et al. 2003). The findings relative to the relationship between nursing education and both RN and NA job satisfaction have been mixed in previous research (Halbur \& Fears 1986, Blegen 1993, Sheward et al. 2005, Li \& Lambert 2008).

\section{The study}

\section{Aim}

The aim of the study was to examine the association between staffing and job satisfaction among RNs and NAs. The research questions for this study are as follows:

- What is the relationship between staffing (i.e. HPPD and skill mix) and job satisfaction of RNs and NAs controlling for demographic variables (e.g. age, gender, nursing education and job experience) and patient acuity [i.e. Case Mix Index (CMI)]?

- Are there any differences as to the significant predictors for job satisfaction between RNs and NAs?

\section{Design}

A cross-sectional correlational design was utilized with the dependent variable being job satisfaction. Explanatory variables included two unit-level staffing variables (i.e. HPPD and skill mix), a measure of patient acuity (CMI) and demographic variables.

\section{Sample and setting}

A purposive sample of 3523 RNs and 1012 NAs made up the sample in this study. The study setting was 131 patient care units in 11 hospitals in Michigan and California including medical-surgical (51.9\%), intensive care $(24.4 \%)$, intermediate $(13.0 \%)$, rehabilitation $(5.3 \%)$, paediatrics and maternity $(3.8 \%)$, and mental health $(1.5 \%)$. Hospital size ranged from 60 to 913 beds. Unit inclusion criteria were an average length of stay $\geq 2$ days and caring for adult patient populations.

\section{Data collection}

Data were collected from November 2008 through to October 2009. All of the surveys were collected within a 4-week time frame for each hospital. Survey packets, which included a cover letter explaining the study, a questionnaire and a return envelope, were distributed to participating nurses. After completing the survey, the nurses placed the anonymous surveys in sealed envelopes and then in locked boxes on each patient care unit. Each participant received a candy bar with the survey, and if units achieved a 50\% response rate or greater, pizza parties were provided to them. Consistent with similar survey studies of this nature in healthcare (Asch et al. 1997), the overall return rate was $57.3 \%$, with response rates ranging from $34.4 \%$ to $99.6 \%$ per unit. The staffing and patient acuity data were collected from each hospital in a raw form (i.e. numerator and denominator) in order to ensure consistency in computation across hospitals. Administrative staff in each hospital were given an Excel file with specific definitions and data requirements and asked to input data into a template designed by the research team. Then, the research team computed all variables of interest.

\section{Measures}

'Satisfaction with current position' was assessed by asking 'How satisfied are you in your current position?' on a Likert scale with anchors 1 ('very dissatisfied') to 5 ('very satisfied'). The test-retest reliability coefficient was 0.84 with a subset $(n=28)$.

HPPD refers to the overall time expended by nursing staff, including RNs and LPNs, and NAs on the unit per patient day. HPPD values were obtained using a standardized data collection tool described above, and then the research team calculated the number of productive hours worked by all nursing staff (RNs, LPNs and NAs) with direct patient care responsibilities divided by in-patient days.

'Skill mix' is defined as the proportion of RNs to total nursing staff including RNs, LPNs and NAs working on a given unit. As endorsed by the National Quality Forum (2010), skill mix was calculated as the number of productive hours worked by the RNs divided by the total number of productive hours worked by nursing staff (RNs, LPNs and NAs).

CMI refers to the average diagnosis-related group (DRG) weight for all of Medicare patients on a given patient care unit. In contrast to hospital level CMI, available through administrative data, each hospital's finance department was asked to calculate a unit-level CMI, using a standardized data collection tool. Although CMI does not measure patient acuity directly, it represents the relative differences in resources expended for patient care. 


\section{Demographic variable}

Age, gender, education level and years of nursing experience were collected from all participants.

\section{Statistical analysis}

Hierarchical linear modelling (HLM) was used to analyse a data structure where nursing staff (level 1) were nested within patient units (level 2). HLM was chosen as an analytical approach to yield more robust estimates than ordinary least-squares regression when nested data were applied (Raudenbush \& Bryk 2002). Of specific interest was the relationship between job satisfaction (level 1 outcome variable) and both staffing (level 2 predictor variable) and demographic variables (level 1 predictor variables). Model specifications of the level 2 HLM regression are as follows:

Level 1: job satisfaction $=\beta_{0 j}+\beta_{1 j}$ (gender $)+\beta_{2 j}$ (education) $+\beta_{3 j}$ (experience $)+\beta_{4 j}($ age $)+\gamma_{i j}$

Level 2: $\beta_{0 \mathrm{j}}=\gamma_{00}+\gamma_{01}(\mathrm{HPPD})_{\mathrm{j}}+\gamma_{02}(\text { Skill mix })_{\mathrm{j}}+$ $\gamma_{03}(\mathrm{CMI})_{\mathrm{j}}+\mu_{0 \mathrm{j}}$

$$
\begin{aligned}
& \beta_{1 \mathrm{j}}=\gamma_{10} \\
& \beta_{2 \mathrm{j}}=\gamma_{20} \\
& \beta_{3 \mathrm{j}}=\gamma_{30} \\
& \beta_{4 \mathrm{j}}=\gamma_{40}
\end{aligned}
$$

Level 1 and level 2 continuous variables (i.e. experience, age, HPPD, skill mix, and CMI) were grandmean centred to alleviate potential level 2 estimation problems as a result of multicolliniearity (Cronbach 1987). The HLM 6.0 software package (Scientific Software International, Inc., Skokie, IL, USA) was utilized for HLM models by job title (i.e. RN and NA).

\section{Results}

Table 1 shows descriptive statistics for level 1 and level 2 variables. Both RNs and NAs were predominantly female and had greater than 2 years of experience. The majority of $\mathrm{RNs}$ held a baccalaureate degree or higher $(57.2 \%)$ whereas the NAs held a high school diploma or associate degree (85.9\%). HPPD values for participating units ranged from a low of 6.27 to a high of 31.99 with the mean being 11.06 [standard deviation $(\mathrm{SD}) \pm 4.51$ ]. The mean skill mix of staff on the units was $0.78(\mathrm{SD} \pm 0.16)$; the mean CMI was 2.03 with a range of 0.83 to 6.93 .

Table 2 contains the HLM results for job satisfaction by job title. For RN job satisfaction, patient unit characteristics (level 2) account for $11.9 \%$ of job satisfaction and $88.1 \%$ of variance in job satisfaction is
Table 1

Descriptive statistics for level 1 and level 2 variables

\begin{tabular}{llrr}
\hline Variable & \multicolumn{1}{c}{ Label } & $R N n(\%)$ & $N A n(\%)$ \\
\hline Level 1 & & $(N=3523)$ & $(N=1012)$ \\
Gender & Male & $275(9.0)$ & $159(15.9)$ \\
& Female & $3174(92.0)$ & $842(84.1)$ \\
Education & Associate degree or less & $1493(42.8)$ & $866(85.9)$ \\
& Bachelor's degree & $1995(57.2)$ & $142(14.1)$ \\
& or higher & & \\
Years of & Up to 6 months & $154(4.4)$ & $60(6.0)$ \\
experience & More than 6 months & $733(20.9)$ & $277(27.6)$ \\
& to 2 years & $674(19.3)$ & $257(25.6)$ \\
& More than 2-5 years & $655(18.7)$ & $195(19.4)$ \\
& More than 5-10 years & $1283(36.7)$ & $216(21.5)$ \\
Age & More than 10 years & $384(10.9)$ & $283(28.1)$ \\
& Under 25 years old & $1130(32.1)$ & $296(29.4)$ \\
& 26-34 years old & $927(26.4)$ & $214(21.3)$ \\
& 35-44 years old & $737(21.0)$ & $154(15.6)$ \\
& 45-54 years old & $338(9.6)$ & $60(6.0)$ \\
\hline Level 2 & 55 years old or older & $(N=131)$ & Mean (SD) \\
\hline HPPD & & $11.06(4.51)$ \\
Skill mix & & $0.78(0.16)$ \\
CMI & & $2.03(1.11)$ \\
\hline RN & & & \\
& & &
\end{tabular}

$\mathrm{RN}$, registered nurse; NA, nursing assistant; HPPD, hours per patient day; CMI, Case Mix Index; SD, standard deviation.

at the individual level (level 1). For NA satisfaction, $11.4 \%$ of variance in job satisfaction is between unit characteristics (level 2) and $88.6 \%$ of the variance in job satisfaction is at the individual level (level 1). Model 1 of the RN and the NA models illustrates the effects of staffing (i.e. HPPD and skill mix) on job satisfaction. The RN model shows that the regression coefficient of HPPD was positive and statistically significant $(b=0.02, P<0.01)$ whereas the NA models show that the skill mix was negatively associated with job satisfaction $(b=-0.57, P<0.05)$. More explicitly, when only staffing variables (i.e. HPPD and the skill mix) were included in the HLM model, HPPD was a significant positive predictor for $\mathrm{RN}$ job satisfaction whereas skill mix was a significant negative predictor for NA job satisfaction.

In model 2, level 1 variables (i.e. gender, age, education and experience) and CMI were added in the analysis. For the RN model, HPPD was still significantly associated with job satisfaction $(b=0.02, P<0.05)$ when other variables were held constant. This means that HPPD was a significant positive predictor for RN job satisfaction after controlling for covariates. For the NA model, experience was negatively associated with job satisfaction $(b=-0.10, P<0.01)$; skill mix was negative and marginally significant $(b=-0.61$, $P=0.058)$. Specifically, as NAs had more experience, 
Table 2

Hierarchical linear modelling (HLM) regressions for job satisfaction of registered nurses (RNs) and nursing assistants $(\mathrm{NAs})(N=4535)$

\begin{tabular}{|c|c|c|c|c|c|c|c|c|c|}
\hline \multirow[b]{2}{*}{ Variable } & \multirow[b]{2}{*}{ Label } & \multicolumn{4}{|c|}{$R N(n=3523)$} & \multicolumn{4}{|c|}{$N A(n=1012)$} \\
\hline & & $B$ & $S E$ & $B$ & $S E$ & $B$ & $S E$ & $B$ & $S E$ \\
\hline Intercept & & $3.91 * *$ & 0.03 & $4.00 * *$ & 0.08 & $3.86 * *$ & 0.04 & $3.93 * *$ & 0.15 \\
\hline \multicolumn{10}{|c|}{ Level 1: Individual characteristics } \\
\hline Gender & Male $(\mathrm{R})$ & & & & & & & & \\
\hline Education & $\begin{array}{l}\text { Bachelor's } \\
\text { degree } \\
\text { or higher }\end{array}$ & & & -0.03 & 0.03 & & & -0.10 & 0.10 \\
\hline Experience & & & & -0.02 & 0.01 & & & $-0.10 * *$ & 0.03 \\
\hline $\mathrm{CMI}$ & & & & -0.01 & 0.03 & & & 0.02 & 0.07 \\
\hline Random effect & & Variance & $\chi^{2}$ & Variance & $\chi^{2}$ & Variance & $\chi^{2}$ & Variance & $\chi^{2}$ \\
\hline Level-2 (intercept) & & 0.08 & $449.76 * *$ & 0.08 & $434.86 * *$ & 0.09 & $199.37 * *$ & 0.09 & $196.46 * *$ \\
\hline Level-1 & & 0.65 & & 0.64 & & 0.70 & & 0.69 & \\
\hline
\end{tabular}

B, coefficient; SE, standard error; HPPD, hours per patient day; CMI, Case Mix Index; R, reference.

$* P<0.05, * * P<0.01$.

job satisfaction decreased after controlling covariates. In addition, when other variables were controlled, a higher skill mix was related to marginally less job satisfaction for NAs.

\section{Discussion}

The results of this study show that for RNs staffing levels are critical in maintaining job satisfaction. These findings add to the previous research which has demonstrated that higher staffing levels as measured by perceptions of adequate staffing, number of patients cared for on the previous shift and skill mix are associated with greater job satisfaction (Adams \& Bond 2000, Aiken et al. 2000, 2002a,b, Shaver \& Lacey 2003, Seo et al. 2004, Sheward et al. 2005, Rafferty et al. 2007, Li \& Lambert 2008). To our knowledge, this is the first study that has utilized HPPD as a measure of staffing. While some of these previous studies controlled for individual demographics and hospital characteristics (Aiken et al. 2002a,b, Sheward et al. 2005), others did not do so (Adams \& Bond 2000, Shaver \& Lacey 2003, Seo et al. 2004,). This study demonstrates that the positive correlation between staffing levels and satisfaction continues even after controlling for patient acuity $(\mathrm{CMI})$ and individual characteristics (i.e. gender, education, experience and age).

In addition, the satisfaction of NAs in acute care hospitals has not been studied before. Previous research has taken place in nursing homes. In this study, we found that the level of actual staffing does not predict NA satisfaction. Instead they are happier when there are more NAs and fewer RNs in the staffing mix. Also the more work experience the NA has, the lower their satisfaction which is not the case for RNs.

For RN satisfaction, staffing levels are paramount. For NAs, however, the number in their own role was the critical factor. This suggests that the NAs feel they have too high of a proportion of the nursing care to do. In addition to the work ethic of the NAs (e.g. they may feel that they should not have to work as hard as they do), this finding could also be because there are too few of them on a unit, or that they are assigned or delegated more work by RNs than is appropriate or doable. The finding that the NAs job satisfaction becomes lower the more years of experience they have points to a problem in the structure and function of this role. Yet it is a vital and essential role in the delivery of acute care hospital nursing services. Turnover of NAs is costly and disruptive of quality.

\section{Conclusion}

\section{Implications}

There are several implications of this study. First, the importance of providing adequate staffing to maintain 
$\mathrm{RN}$ and NA job satisfaction is evident. Balancing the cost of staffing and the job satisfaction of nursing staff is a major on-going challenge for nurse managers and hospital administrators. Given the findings of this study, consideration needs to be given to the high cost of turnover. Saving money by reducing nurse staffing to an inadequate level can potentially lead to higher costs and lower quality.

While the RNs were more dissatisfied when staffing overall was perceived to be inadequate, the NAs focused specifically on the number of NAs. This finding suggests that there is a distinct division between $\mathrm{RN}$ and NA responsibilities and tasks ('RN work' $v$ s. 'NA work') as opposed to 'our work. When this is the case, the NAs could be overloaded or perceive that they are given an unfair share of the work, leading to dissatisfaction. More importantly, this finding points to a lack of teamwork between these two categories of nursing personnel. In other previous studies, we have found significant teamwork problems between RNs and NAs (Kalisch et al. 2009, Kalisch 2011).

The finding that NAs job satisfaction decreased with time adds to the conclusion that there are problems inherent in the way nursing teams work together, the model of care utilized, how they allocate work, the extent of NA engagement and participation in decision making, the recognition given to NAs and other factors. Major efforts need to be expended by nurse managers to improve the structure and functioning of the nursing team with special emphasis on the $\mathrm{RN}-\mathrm{NA}$ dyad. The approach needs to include staff engagement and enhanced teamwork leading to nursing staff working more productively and effectively together (Kalisch et al. 2007).

In a study the first author conducted to enhance teamwork and engagement, it was found that the intervention resulted in a significant drop in patient falls and staff turnover and vacancy rate (Kalisch et al. 2007). This intervention, while very successful, took a considerable amount of resources to implement (i.e. staff time, facilitator time etc.). Currently the first author is conducting studies utilizing a much shorter intervention designed to take place on the patient unit. Preliminary results show promise that nursing staff can be taught how to work as a team and facilitated to do so. The nurse manager is a key in this effort. These individuals need training in methods of team facilitation.

\section{Limitations}

There are several limitations of this study. First the data were collected in 11 hospitals in two states and cannot be generalized to the entire country. Second, the crosssectional design of the study limits our ability to predict causality. In addition, job satisfaction was measured by single-item scales, which might ignore some aspects of job satisfaction. However, research has reported that single-item measures showed acceptable reliability and validity and might be a holistic way to measure perceptions of participants (Youngblut \& Casper 1993, Wanous et al. 1997).

\section{Acknowledgements}

The authors thank Seung Hee Lee and Hyunhwa Lee for their contributions to this project.

\section{Conflict of interest}

The authors attest there are no conflicts of interest with the manuscript.

\section{Source of funding}

This study was funded by a grant from the Blue Cross Blue Shield Foundation of Michigan.

\section{Ethical approval}

The study was approved by the university and all participating hospitals. All participation was voluntary and informed consent was obtained. Participants were also informed about confidentiality.

\section{References}

Adams A. \& Bond S. (2000) Hospital nurses' job satisfaction, individual and organizational characteristics. Journal of Advanced Nursing 32 (3), 536-543.

Aiken L.H. \& Patrician P. (2000) Measuring the organizational traits of hospitals: the revised nursing work index. Nursing Research 49 (3), 146-153.

Aiken L.H., Havens D.S. \& Sloane D.M. (2000) The magnet nursing services recognition program: a comparison of two groups of magnet hospitals. American Journal of Nursing, 100 (3), 26-36.

Aiken L.H., Clarke S. \& Sloane D. (2002a) Hospital staffing, organization, and quality of care: cross-national findings. International Journal for Quality in Health Care 14 (1), 5-14.

Aiken L.H., Clarke S.P., Sloane D.M., Sochalski J. \& Silber J.H. (2002b) Hospital nurse staffing and patient mortality, nurse burnout, and job dissatisfaction. JAMA 288 (16), 1987 $-1993$.

Anderson T., Linden L., Allen M. \& Gibbs E. (2009) New graduate $\mathrm{RN}$ work satisfaction after completing an interactive nurse residency. Journal of Nursing Administration 39 (4), 165-169. 
Asch D.A., Jedrziewski M.K. \& Christakis N.A. (1997) Response rates to mail surveys published in medical journals. Journal of Clinical Epidemiology 50 (10), 1129-1136.

Best M.F. \& Thurston N.E. (2004) Measuring nurse job satisfaction. Journal of Nursing Administration 34 (6), 283-290.

Bjork I., Samdal G., Hansen B., Torstad S. \& Hamilton G. (2007) Job satisfaction in a Norwegian population of nurses: a questionnaire survey. International Journal of Nursing Studies 44 (5), 747-757.

Blegen M.A. (1993) Nurses' job satisfaction: a meta-analysis of related variables. Nursing Research 42 (1), 36-41.

Castle N.G. \& Engberg J. (2005) Staff turnover and quality of care in nursing homes. Medical Care 43 (6), 616-626.

Castle N.G., Engberg J., Anderson R. \& Men A. (2007) Job satisfaction of nurse aides in nursing homes: intent to leave and turnover. The Gerontologist 47 (2), 193-204.

Cronbach L.J. (1987) Statistical tests for moderator variables: flaws in analyses recently proposed. Psychological Bulletin 102 (3), 414-417.

Dunn S., Wilson B. \& Esterman A. (2005) Perceptions of working as a nurse in an acute care setting. Journal of Nursing Management 13 (1), 22-31.

Halbur B.T. \& Fears N. (1986) Nursing personnel turnover rates turned over: potential positive effects on resident outcomes in nursing homes. The Gerontologist 26 (1), 70-76.

Kalisch B. (2011) The impact of RN-UAP relationships on quality and safety. Nursing Management 42 (9), 16-22.

Kalisch B., Curley B. \& Stefanov S. (2007) An intervention to enhance nursing teamwork and engagement. Journal of Nursing Administration 37 (2), 77-84.

Kalisch B., Weaver S. \& Salas E. (2009) What does nursing teamwork look like? A qualitative study Journal of Nursing Care Quality 24 (4), 298-307.

Kalisch B., Tschanen D. \& Lee H. (2011) Does missed nursing care predict job satisfaction? Journal of Healthcare Management 56 (2), 117-131.

Khowaja K., Merchant R.J. \& Hirani D. (2005) Registered nurses perception of work satisfaction at a tertiary care university hospital. Journal of Nursing Management 13 (1), 32-39.

Lapane K.L. \& Hughes C.M. (2007) Considering the employee point of view: perceptions of job satisfaction and stress among nursing staff in nursing homes. Journal of the American Medical Directors Association 8 (1), 8-13.

Li J. \& Lambert V.A. (2008) Job satisfaction among intensive care nurses from the people's republic of china. International Nursing Review 55 (1), 34-39.
Murrells T., Clinton M. \& Robinson S. (2005) Job satisfaction in nursing: validation of a new instrument for the UK. Journal of Nursing Management 13 (4), 296-311.

National Quality Forum (2010) Nursing care hours per patient day (RN, LPN, and UAP) [WWW document]. Available at: http://www.qualityforum.org/Standards/Measures/Nursing_care_ hours_per_patient_day_(RN,_LPN,_and_UAP).aspx, accessed 20 January 2010.

Parsons S., Simmons W., Penn K. \& Furlough M. (2003) Determinants of satisfaction and turnover among nursing assistants. The results of a statewide survey. Journal of Gerontological Nursing 29 (3), 51-58.

Rafferty A.M., Clarke S.P., Coles J. et al. (2007) Outcomes of variation in hospital nurse staffing in English hospitals: crosssectional analysis of survey data and discharge records. International Journal of Nursing Studies 44 (2), 175-182.

Raudenbush S.W. \& Bryk A.S. (2002) Hierarchical Linear Models: Applications and Data Analysis Methods, 2nd edn. Sage Publilcations, London.

Rochefort C.M. \& Clarke S.P. (2010) Nurses' work environments, care rationing, job outcomes, and quality of care on neonatal units. Journal of Advanced Nursing 66 (10), 22132224.

Seago J.A. (2002) The California experiment: alternatives for minimum nurse-to-patient ratios. The Journal of Nursing Administration 32 (1), 48-58.

Seo Y., Ko J. \& Price J. (2004) The determinants of job satisfaction among hospital nurses: a model estimation in Korea. International Journal of Nursing Studies 41 (4), 437-446.

Shaver K.H. \& Lacey L.M. (2003) Job and career satisfaction among staff nurses: effects of job setting and environment. The Journal of Nursing Administration 33 (3), 166.

Sheward L., Hunt J., Hagen S., Macleod M. \& Ball J. (2005) The relationship between UK hospital nurse staffing and emotional exhaustion and job dissatisfaction. Journal of Nursing Management 13 (1), 51-60.

Wallace R.W. \& Brubaker T.H. (1982) Biographical factors related to employment tenure: a study of nurse aides in nursing homes. Journal of Long Term Care Administration 10 (2), 11-19.

Wanous J.P., Reichers A.E. \& Hudy M.J. (1997) Overall job satisfaction: how good are single-item measures? Journal of Applied Psychology 82 (2), 247-252.

Youngblut J.M. \& Casper G.R. (1993) Focus on psychometrics single-item indicators in nursing research. Research in Nursing \& Health 16 (6), 459-465. 